\title{
Myzus persicae Feeding on Water Stressed-Arabidopsis Affects the Emission Profile of Plant Volatile Organic Compounds
}

\author{
Dieu-Hien Truong (Corresponding author) \\ Laboratory of Analytical Chemistry, Unit of Analysis Quality and Risk, University of \\ Liège, Gembloux Agro-Bio Tech, Belgium \\ Functional \& Evolutionary Entomology Laboratory, University of Liège, Gembloux \\ Agro-Bio Tech, Belgium \\ Biotechnology Faculty, Binh Duong University, Vietnam \\ Tel: 32-816-222-181 E-mail: ttdhienvn83@gmail.com
}

\section{Pierre Delaplace}

Plant Biology Laboratory, University of Liège, Gembloux Agro-Bio Tech, Belgium E-mail: pierre.delaplace@ulg.ac.be

\section{Yves Brostaux}

Unit of Applied Statistic, Computer Science and Mathematics, University of Liège, Gembloux Agro-Bio Tech, Belgium

E-mail: y.brostaux@ulg.ac.be

\section{Stéphanie Heuskin}

Laboratory of Analytical Chemistry, Unit of Analysis Quality and Risk, University of Liège, Gembloux Agro-Bio Tech, Belgium

E-mail: stephanie.heuskin@ulg.ac.be

Frédéric Francis

Functional \& Evolutionary Entomology Laboratory, University of Liège, Gembloux Agro-Bio Tech, Belgium

E-mail: frederic.francis@ulg.ac.be 


\title{
Georges Lognay
}

Laboratory of Analytical Chemistry, Unit of Analysis Quality and Risk, University of Liège, Gembloux Agro-Bio Tech, Belgium

Email: georges.lognay@ulg.ac.be

Received: November 18, 2014 Accepted: December 2, 2014 Published: December 31, 2014

doi:10.5296/jee.v5i2.6848ＵRL: http://dx.doi.org/10.5296/jee.v5i2.6848

\begin{abstract}
Emissions of volatile organic compounds (VOCs) by water-controlled or water-stressed Arabidopsis thaliana infested or not infested with Myzus persicae were evaluated by headspace solid phase microextraction (HS-SPME) coupled with gas chromatography-mass spectrometry (GC-MS). The infestations were maintained for $0-24 \mathrm{~h}, 24-48 \mathrm{~h}$, and $48-72 \mathrm{~h}$, and the emission profile for each time period was determined. Under these controlled conditions, the proportion of 4-methylpentyl isothiocyanate and dimethyl disulfide emitted by aphid-infested, water-stressed Arabidopsis was greater than that for aphid-infested water-controlled Arabidopsis over the 48-72 h sampling period. The proportion of terpene emitted by aphid-infested water-stressed plants also significantly increased compared with the other treatments over the three assayed sampling periods. In contrast, the proportion of 2-ethylhexanal (the only detected aldehyde) and ketones for the water-controlled plants generally remained high following aphid infestation. Taken together, these original data ascertain that abiotic factors can greatly interact to biotic stresses to alter the VOC emission profiles of plants.
\end{abstract}

Keywords: Arabidopsis thaliana, Myzus persicae, water stress, water control, volatile organic compounds (VOCs) 


\section{Introduction}

Plants often release a wide variety of volatile organic compounds (VOCs) during their life cycle, and these can also differ significantly according to plant species, developmental stage, and environmental conditions (Dicke et al., 2009; Vickers et al., 2009; Holopainen and Gershenzon, 2010; Loreto and Schnitzler, 2010). Regarding the latter, both abiotic and biotic stresses can affect the emission profile of volatile compounds from plants (Van Poecke, 2007; Hatano et al., 2008; Holopainen and Gershenzon, 2010; Copolovici et al., 2012; Niinemets et al., 2013).

Water stress is considered to be the most important environmental factor which directly influences the physiological and biochemical processes of plants (Niinemets et al., 2004; Loreto and Schnitzler, 2010). Under drought conditions, the emission of VOCs from the leaves of Mediterranean species has been found to be: (i) unmodified (Peñuelas and Llusià, 1997); (ii) inhibited (Llusia and Penuelas, 1998); or (iii) reduced (Staudt et al., 2002). However, in other studies, water stress was found to increase VOC emissions from apple trees (Ebel et al., 1995; Vallat et al., 2005). Thus, the effect of water stress on plant VOC emission is not consistent throughout the literature and depends on the plant species and the considered biological model (Holopainen and Gershenzon, 2010; Loreto and Schnitzler, 2010).

The release of VOCs has been shown to depend on either stomatal behavior or the polarity of the compounds (Tholl et al., 2006; Loreto and Schnitzler, 2010). For example, the impact of abiotic factors (e.g., drought and salt) on plants can lead to a reduction in photosynthesis and stomatal closure, which can lead to changes in terpene emission by affecting the carbon supply into the 2-C-methyl-D-erythritol 4-phosphate (MEP) pathway (Loreto and Schnitzler, 2010). Jones (1998) and Tardieu and Simonneau (1998) have also reported that the behavior of the stoma changes according to a plant's water status.

Herbivorous insects are well-documented biotic factors that affect the emission of plant volatile blends (Van Poecke, 2007; Dicke et al., 2009; Holopainen and Gershenzon, 2010; Kos et al., 2012; Louis et al., 2012). Of these, phloem-feeding insects can cause minor damage to plant foliage following infestations due to their salivary chemicals and/or proteins that act as signaling factors to affect the biosynthesis of volatile compounds by plants (Walling, 2000; De Vos and Jander, 2009). Studies of aphid-fed Arabidopsis thaliana (L.) Heynh (A. thaliana) have shown that these the plant systemic acquired resistance (SAR) are induced as a pest avoidance mechanism via the salicylate (SA) signaling pathway to release VOCs (e.g., terpenoids and glucosinolate (GS) metabolites) (Vallad and Goodman, 2004; Van Poecke, 2007; De Vos and Jander, 2010; Louis et al., 2012). As a host plant of green peach aphids (Myzus persicae), variations in the emission profile of volatiles from Arabidopsis due to aphid feeding is well-documented (Mewis et al., 2005; Kim and Jander, 2007; Van Poecke, 2007; De Vos and Jander, 2009; Louis et al., 2012; Truong et al., 2014). In particular, Mewis et al. (2005) have reported that the emission of indole GS from Arabidopsis plants increases with aphid $M$. persicae infestation.

In nature, plants are often subjected to multiple stress factors which can affect VOC emission 
patterns (Wenda-Piesik, 2011; Mewis et al., 2012; Suzuki et al., 2014). Furthermore, VOCs play an important role in eliciting priming and in determining the integrated responses of plant responses to biotic, abiotic, or subsequent herbivorous stresses (Copolovici et al., 2014). Here, A. thaliana plantlets were submitted to both controlled and stressed water conditions prior to infestation by $M$. persicae, and uninfested plants were used as controls. The objective was to evaluate changes in the VOC emission profiles of Arabidopsis under various stress conditions, including combined biotic and abiotic stresses.

\section{Materials and Methods}

\subsection{Plants and Insects}

A. thaliana (Col-0) seeds (Lehle Company, TX, USA) were sown in plastic pots (0.2 1) with potting soil (DCM, Belgium) and were cultivated in a growth chamber at $22 \pm 0.6{ }^{\circ} \mathrm{C}, 16 \mathrm{~L}$ : 8D (LED lighting: $43 \mu \mathrm{mol} \mathrm{m} \mathrm{m}^{-2}$ photosynthetically active radiation during the light period), and $64.5 \pm 2.6 \%$ relative humidity $(\mathrm{RH})$. The green peach aphid, M. persicae (Sulzer), was reared on broad bean plants (Vicia faba L.) under controlled environmental conditions in a room at $20 \pm 2{ }^{\circ} \mathrm{C}$ with a $16 \mathrm{~L}$ : $8 \mathrm{D}$ photoperiod. Seedlings were watered twice a week for three weeks with the same volume of tap water $(10-15 \mathrm{ml} / \mathrm{pot})$ before being subjected to different water stress treatments. No morphological or growth differences were reported between the plants.

\subsection{Experimental Design}

Three-week-old Arabidopsis seedlings were watered to $100 \%$ of field capacity (FC) level (water-controlled) or to $50 \%$ of FC level (water-stressed). FC is the amount of water remaining in the soil after excess water has drained and the rate of downward movement is reduced (Diallo and Mariko, 2013).

Field capacity levels were calculated according to the method suggested by Verdugo (2012) and Sales et al. (2013). Particularly, FC was estimated by saturating the plastic pot containing plant and soil with water. These pots were weighted after $36 \mathrm{~h}$ to obtain the average weight that corresponded to the FC. This value was defined as water control level (100\% FC). The determination of water refill for all water levels (50 and $100 \%$ FC) was calculated based on this value. To maintain FC levels in the different water regimes, all potted plants were weighted every $24 \mathrm{~h}$ and their water content was adjusted according to the requested value.

Two weeks after the start of the water treatments, $M$. persicae were randomly placed on three water-controlled plants and three water-stressed plants to initiate conditions representing aphid stress. Seventy adults $M$. persicae were applied per plant according to Truong et al. (2014). Additional water-controlled and water-stressed plants were left without aphid treatment as controls. The aphids were left to feed on the leaves for three different time periods: 0-24 h, 24-48 h, and 48-72 h. Each treatment was performed in three biological replicates.

Prior to the application of aphids, the Arabidopsis, including root balls (9-10 leaves, $0.25-0.40 \mathrm{~g} /$ plant), were carefully removed from their plastic pots and aluminum foil was 
wrapped around the root balls to reduce the detection of soil volatiles. Groups of three plants were then carefully placed in the reaction vessels (100 ml volume, Duran Group, Germany). Prior to their use, the reaction vessels were carefully cleaned with methanol, followed by milli-Q water, and then placed in an oven at $180{ }^{\circ} \mathrm{C}$ for $24 \mathrm{~h}$ in order to eliminate traces of contaminants.

\subsection{Headspace VOC Collection and GC-MS Analysis}

Similar to our recent study on the effect of temperature-herbivorous interactions on Arabidopsis volatile emissions (Truong et al., 2014), headspace solid phase microextraction (HS-SPME) using polydimethylsiloxane/divinylbenzene (PDMS/DVB) fibers $(65 \mu \mathrm{m}$; Supelo, Bellefonte, PA, USA) was performed. Briefly, volatile collection from Arabidopsis exposed to different stress treatments was performed over three time periods, $0-24 \mathrm{~h}, 24-48 \mathrm{~h}$, and 48-72 h, with HS-SPME samplings collected six hours before the end of each period. In order to avoid contamination, the fibers were conditioned at $225^{\circ} \mathrm{C}$ for 30 min prior to the onset of VOC collection.

After the given sampling time, the fibers were desorbed during $5 \mathrm{~min}$ in a splitless injector $\left(220^{\circ} \mathrm{C}\right.$ ) of a gas chromatograph (GC) (Trace GC Ultra) coupled to a quadrupole-type mass spectrometer Trace Finnigan (Thermo-Fisher Scientific; Waltham, MA, USA). The GC was equipped with an apolar column (30 m; $0.25 \mathrm{~mm}$ inner diameter; $0.25 \mu \mathrm{m}$ film thickness) (Optima-5-MS, Macherey-Nagel, Düren, Germany). The oven temperature program included a temperature increase from $40{ }^{\circ} \mathrm{C}$ to $220{ }^{\circ} \mathrm{C}$ (at a rate of $4{ }^{\circ} \mathrm{C} \mathrm{min}^{-1}$ ) followed by a $1 \mathrm{~min}$ hold, and then an increase from $220{ }^{\circ} \mathrm{C}$ to $320{ }^{\circ} \mathrm{C}$ (at a rate of $100{ }^{\circ} \mathrm{C} \mathrm{min}{ }^{-1}$ ) followed by a 10 min hold. Helium was used as the carrier gas (at a constant flow rate of $1.5 \mathrm{ml} \mathrm{min}^{-1}$ ). Mass spectra were obtained using a mass selective detector operating in electron ionization mode at $70 \mathrm{eV}$ with a multiplier voltage of $275 \mathrm{~V}$. The scanned mass range was from 39 to 400 atomic mass units (amu) at a rate of one scan s${ }^{-1}$. The transfer line and ion source temperatures were maintained at $230{ }^{\circ} \mathrm{C}$ and $250{ }^{\circ} \mathrm{C}$, respectively. Volatile components were identified based on their retention times. The main peaks in the spectra were also compared with the Wiley and NIST MS 2.0 computed spectral databases. Blank samples were regularly analyzed to monitor the possibility of sample carry over and to confirm the peaks originating from the fibers.

\subsection{Statistical Analysis}

The relative abundance of individual VOCs was expressed as a ratio between their peak area and the total area of all identified VOCs from Arabidopsis plants subjected to each treatment. In a second step, the proportions of the chemical classes detected (i.e., alcohols, aldehyde, ketones, isothiocyanate (ITC), sulfide, and terpenes) were calculated.

To evaluate the variations between the volatile blends emitted by the Arabidopsis plants exposed to different stress treatments over the three assayed time periods, principal component analysis (PCA) was performed using Minitab® 16.2.2 software (State College, PA, USA). PCA was applied to a dataset containing the mean relative abundances of the individual VOCs for each experimental treatment, and the principal components (PCs) were 
calculated using a correlation matrix.

ANOVAs (three-way) and subsequent post hoc Tukey's tests using Minitab ${ }^{\circledR}$ 16.2.2 software were conducted to compare the mean relative abundances of the individual VOCs, as well as the relative proportions of the VOC chemical families emitted by the plants following various stress treatments, after the three time periods. For each subset, a $\log (x+1)$ transformation of the data was performed when necessary in order to meet assumptions of normality and homogeneity of variances.

\section{Results}

Table 1 lists the VOCs that were identified by HS-SPME-GC-MS from aphid-infested and non-infested water-stressed and water-controlled Arabidopsis over three sampling periods that spanned $72 \mathrm{~h}$. A total of ten volatile compounds were identified: 1-octen-3-ol, 2-ethylhexan-1-ol, 2-ethylhexanal, 6-methyl hept-5-en-2-one, octan-2-one, 4-methylpentyl ITC, dimethyl disulfide (DMDS), limonene, menthol, and (E,E)- $\alpha$-farnesene (Table 1).

PCA resulted in the variations in the VOC emission profiles of the water-controlled and water-stressed Arabidopsis plants. In particular, PCA using the mean proportion of each individual compound captured $64.8 \%$ of the total variance on the score plot constructed with the two first PCs (e.g., PC1: $48.1 \%$ and PC2: 16.7\%; Figure 1). Statistical correlations between the variables and the PCs (based on the PC1 and PC2 score plots) showed that DMDS (PC1: 0.77; PC2: -0.25), 1-octen-3-ol (PC1: 0.71; PC2: -0.13), 4-methylpentyl ITC (PC1: 0.68; PC2: -0.34), limonene (PC1: 0.60; PC2: -0.61), and 6-methyl hept-5-en-2-one (PC1: 0.56; PC2: -0.27 ) positively correlated with PC1, and negatively correlated with PC2. In contrast, menthol (PC1: -0.62; PC2: 0.02) and 2-ethylhexan-1-ol (PC1: -0.87; PC2: 0.15) negatively correlated with PC1 and positively correlated with PC2. Both PC1 and PC2 positively correlated with (E,E)- $\alpha$-farnesene (PC1: 0.76; PC2: 0.54), octan-2-one (PC1: 0.71; PC2: 0.56), and 2-ethylhexanal (PC1: 0.58; PC2: 0.63).

PCA allowed spatial visualization of the chemical profiles emitted by the water-controlled and water-stressed Arabidopsis plants prior to with or without infestations by M. persicae over the three time periods into two groups (Figure 1). Group 1 primarily consisted of the VOC emission profiles from both water-controlled and water-stressed Arabidopsis without aphid feeding over the three time periods. In addition, volatile blends released by aphid-infested water-controlled plants after the first time course were also included in Group 1. Group 2 included the VOC emission profiles of the water-controlled and water-stressed plants infested by aphids after all three time periods. The coefficients of correlation between the PCs and the variables indicated that the VOC emission profiles released from Arabidopsis in Group 1 were characterized by menthol and 2-ethylhexan-1-ol. In contrast, the VOC emission profiles for Group 2 were characterized by the presence of DMDS, 1-octen-3-ol, 4-methylpentyl ITC, limonene, 6-methyl hept-5-en-2-one, $(E, E)$ - $\alpha$-farnesene, octan-2-one, and 2-ethylhexanal. 


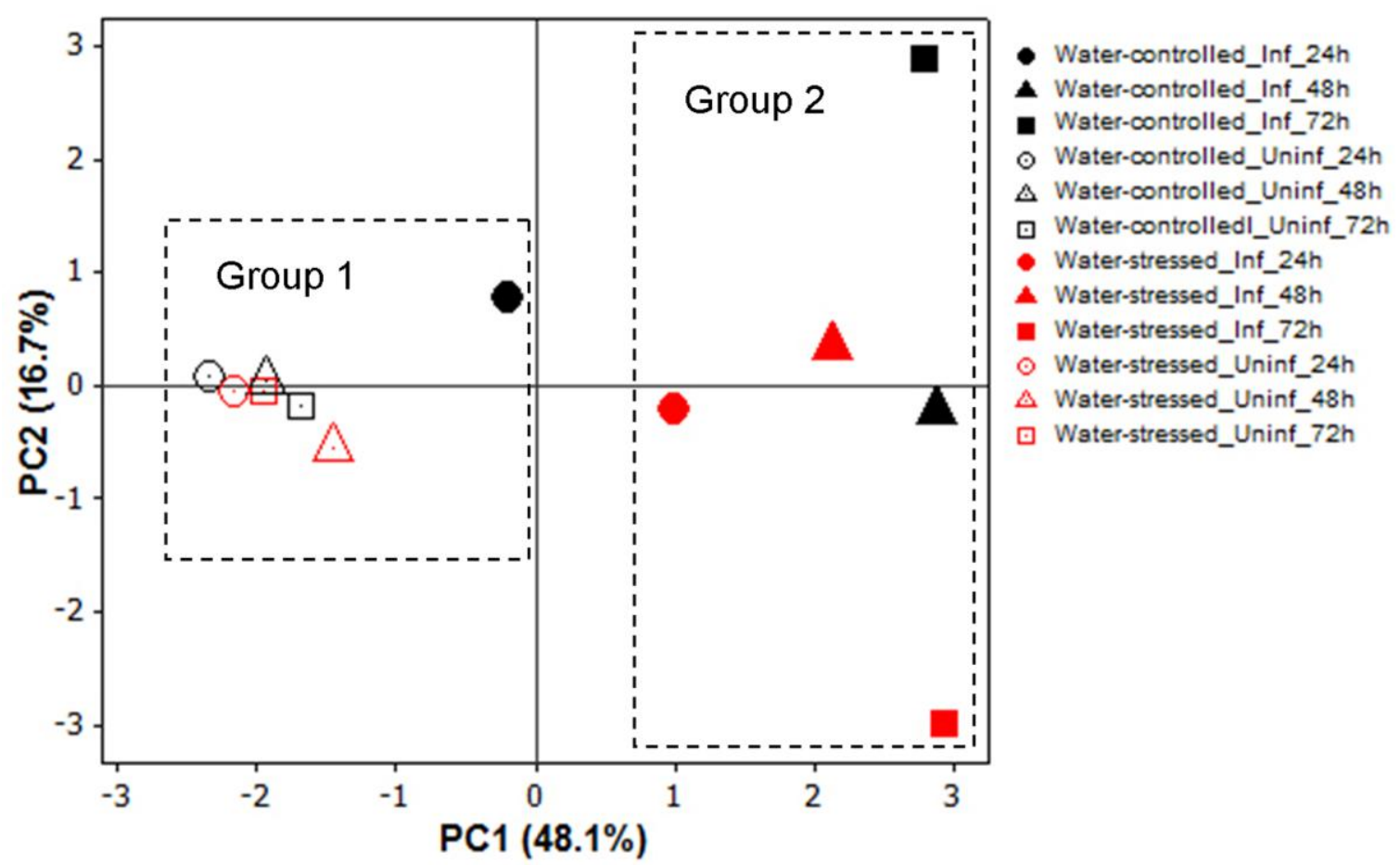

Figure 1. PCA of the VOC emission profiles of water-controlled (black) and water-stressed (red) A. thaliana prior to with or without infestations by $M$. persicae over three sampling periods (0-24 h, 24-48 h, and 48-72 h). The first (PC1) and second (PC2) principal components are shown.

Abbreviations: Uninf: Uninfested; Inf: infested: sampling period 0-24 h (24 h), sampling period 24-48 h (48 h); and sampling period 48-72 h (72 h).

Three-way ANOVAs, followed by post hoc Tukey's test, showed that the alcohols represented the largest proportion of the volatile profile obtained for the uninfested water-controlled plants for the 24-48 h sampling period compared with the other stress treatments $(\mathrm{p}<0.001)$ (Figure 2A). With respect to individual compounds, a significant increase in the proportion of 2-ethylhexan-1-ol was also observed for uninfested water-controlled Arabidopsis over the second time period compared with the stress treatments ( $\mathrm{p}<0.001)$. In contrast, 1-octen-3-ol was only detected in VOC emission profiles of the infested water-controlled and water-stressed plants after the 48-72 h sampling period ( $\mathrm{p}<0.001$; Table 1).

The only detected aldehyde, 2-ethylhexanal ( $\mathrm{p}<0.001$, Figure $2 \mathrm{~B}$ and Table 1), and the ketones, 6-methyl hept-5-en-2-one and octan-2-one ( $\mathrm{p}=0.005$, Figure $2 \mathrm{C}$ and Table 1$)$, constituted the highest proportions of the VOCs detected when the water-controlled plants were infested by $M$. persicae compared with the other stress conditions over the $24-48 \mathrm{~h}$ sampling period. Furthermore, 6-methyl hept-5-en-2-one, had the highest levels of the VOCs emitted by the infested water-controlled plants $(\mathrm{p}<0.001)$, whereas octan-2-one was only emitted by the infested water-stressed plants $(\mathrm{p}<0.001)$ (Table 1$)$.

GS derivative volatiles (e.g., ITC and sulfide) were only emitted by infested plants (Figure 2, D \& E). In particular, 4-methylpentyl ITC (the only ITC detected, $p<0.001$ ) and DMDS (the only sulfide detected, $p<0.001$ ) constituted the highest proportion of the VOCs emitted from 


\section{Macrothink}

the water-stressed plants infested by $M$. persicae over the 48-72 h sampling period (Table 1).

The relative abundance of terpenes significantly increased when the water-stressed Arabidopsis were subjected to aphid infestations compared to the other stress treatments over the 48-72 h sampling period ( $\mathrm{p}<0.001$; Figure $2 \mathrm{~F}$ ). With respect to the single compounds, the proportion of limonene emitted was the highest for the infested water-stressed Arabidopsis during the $48-72 \mathrm{~h}$ sampling period ( $\mathrm{p}<0.001$ ), while the proportion of menthol emitted was the highest for the uninfested water-stressed plants during the $0-24 \mathrm{~h}$ sampling period $(\mathrm{p}=0.005)$. Emission of $(E, E)$ - $\alpha$-farnesene was detected for infested Arabidopsis during all three sampling periods $(\mathrm{p}<0.001$; Table 1$)$.

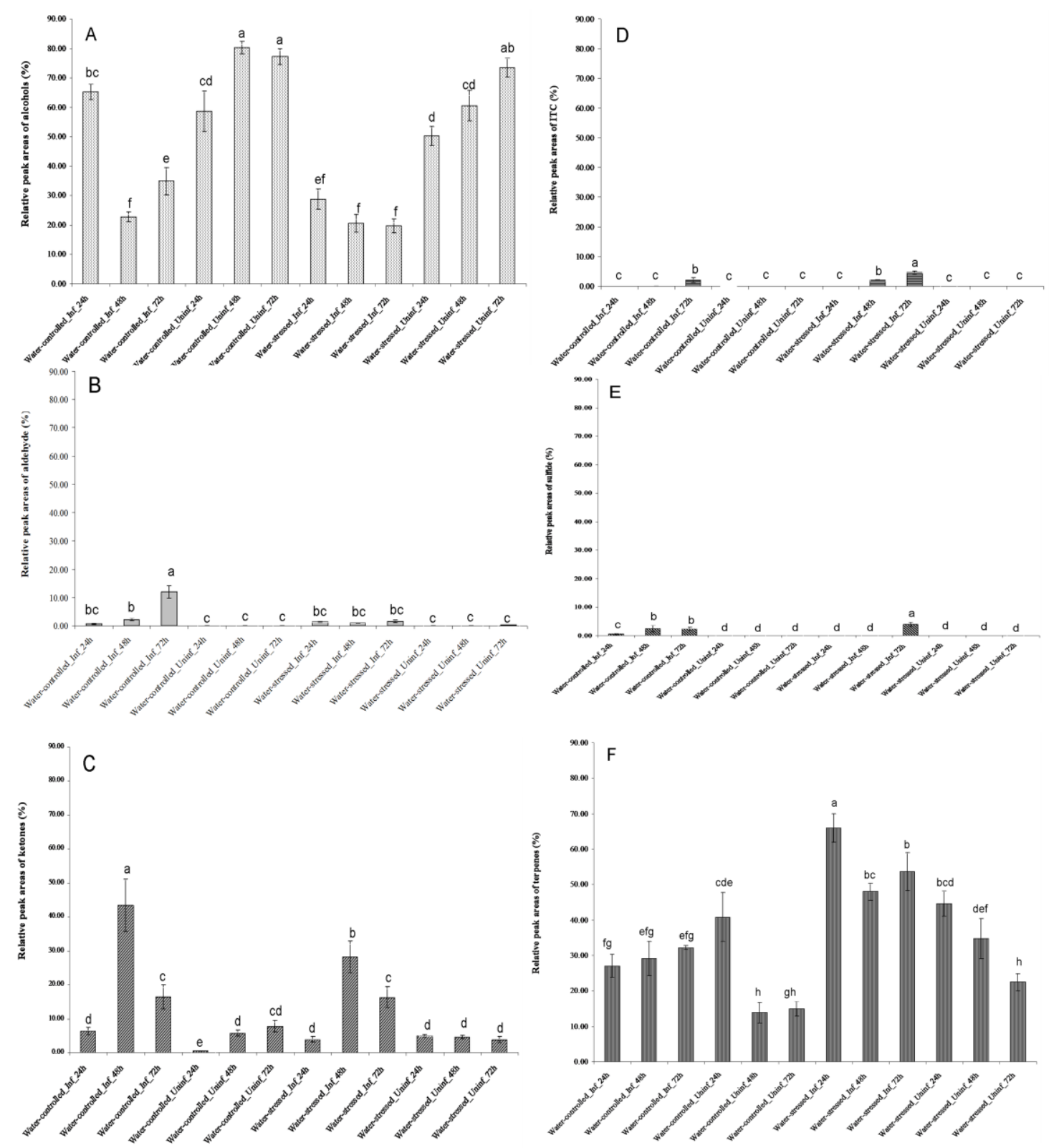

Figure 2. Mean relative abundance $(\% \pm S D ; n=3)$ of each VOC chemical family emitted by the water-controlled and water-stressed $A$. thaliana prior to infestation by $M$. persicae over 
the three assayed sampling periods (e.g., 0-24 h, 24-48 h, and 48-72 h).

Uninf: uninfested plants; Inf: infested plants. Values labeled with the same letter did not statistically differ ( $\mathrm{p}>0.05$, three-way ANOVA, post hoc Tukey's HSD test).

Table 1. Mean relative abundance ( $\% \pm$ standard deviation $(\mathrm{SD}) ; \mathrm{n}=3)$ of VOCs emitted by water-controlled and water-stressed $A$. thaliana prior to infestation by $M$. persicae over three sampling periods (0-24 h, 24-48 h, and 48-72 h)

\begin{tabular}{|c|c|c|c|c|c|c|c|c|c|c|c|c|}
\hline \multirow{3}{*}{ Compound } & \multicolumn{12}{|c|}{ VOC proportion (\%) } \\
\hline & \multicolumn{3}{|c|}{ Infested water-controlled } & \multicolumn{2}{|c|}{ Uninfested water-controlled } & \multicolumn{3}{|c|}{ Infested water-stressed } & \multicolumn{4}{|c|}{ Uninfested water-stressed } \\
\hline & $0-24 h$ & $24-48 h$ & $48-72 h$ & $0-24 h$ & $24-48 h$ & $48-72 h$ & $0-24 h$ & $24-48 \mathrm{~h}$ & $48-72 h$ & $0-24 h$ & $24-48 h$ & $48-72 h$ \\
\hline \multicolumn{12}{|l|}{ Alcohols } & \multirow[b]{2}{*}{ nd } \\
\hline 1-Octen-3-ol & $1.70 \pm 0.16^{\mathrm{bc}}$ & $3.27 \pm 1.00^{\mathrm{a}}$ & $0.60 \pm 0.02^{\mathrm{d}}$ & nd & nd & nd & $2.90 \pm 0.25^{\mathrm{ab}}$ & $1.12 \pm 0.23^{\mathrm{cd}}$ & $1.46 \pm 0.94^{\mathrm{cd}}$ & nd & nd & \\
\hline 2-Ethylhexan-1-ol & $63.57 \pm 2.41^{\mathrm{bc}}$ & $19.44 \pm 1.52^{\mathrm{f}}$ & $34.31 \pm 4.65^{\mathrm{d}}$ & $58.59 \pm 6.90^{\text {cd }}$ & $80.32 \pm 2.16^{\mathrm{a}}$ & $77.22 \pm 2.62 \mathrm{a}$ & $25.80 \pm 3.22 \mathrm{ef}$ & $19.46 \pm 2.96^{\mathrm{f}}$ & $18.34 \pm 2.26^{6}$ & $50.31 \pm 3.24^{\mathrm{d}}$ & $60.52 \pm 5.15^{\mathrm{cd}}$ & $73.52 \pm 3.18^{\mathrm{ab}}$ \\
\hline Total alcohols & $65.27 \pm 2.50^{\mathrm{bc}}$ & $22.72 \pm 1.72^{\mathrm{f}}$ & $34.91 \pm 4.63^{e}$ & $58.59 \pm 6.90^{\mathrm{cd}}$ & $80.32 \pm 2.17^{\mathrm{a}}$ & $77.22 \pm 2.63^{\mathrm{a}}$ & $28.70 \pm 3.41$ ef & $20.58 \pm 3.00^{f}$ & $19.79 \pm 2.30^{f}$ & $50.31 \pm 3.25^{\mathrm{d}}$ & $60.52 \pm 5.16^{\mathrm{cd}}$ & $73.52 \pm 3.19^{\mathrm{ab}}$ \\
\hline \multicolumn{12}{|l|}{ Aldehyde } & \multirow[b]{2}{*}{$0.12 \pm 0.03^{\mathrm{c}}$} \\
\hline 2-Ethylhexanal & $0.64 \pm 0.20^{\mathrm{bc}}$ & $2.19 \pm 0.49^{\mathrm{b}}$ & $11.95 \pm 2.31^{a}$ & trace & trace & trace & $1.31 \pm 0.25^{\mathrm{bc}}$ & $1.03 \pm 0.15^{\mathrm{be}}$ & $1.53 \pm 0.48^{\mathrm{bec}}$ & trace & trace & \\
\hline
\end{tabular}

VOC $=$ volatile organic compound; nd $=$ not detected; trace $(<0.05 \%)$. For each individual VOC or each chemical family, mean values labeled with the same letter in the same row did not statistically differ ( $\mathrm{p}>0.05$, three-way ANOVA, post hoc Tukey's honest significance difference (HSD) test).

Table 1 (continued). Mean relative abundance ( $\% \pm \mathrm{SD} ; \mathrm{n}=3)$ of VOCs emitted by water-controlled and water-stressed A. thaliana prior to infestation by $M$. persicae over three sampling periods (0-24 h, 24-48 h, and 48-72 h)

\begin{tabular}{|c|c|c|c|c|c|c|c|c|c|c|c|c|}
\hline \multirow{3}{*}{ Compound } & \multicolumn{12}{|c|}{ VOC proportion (\%) } \\
\hline & \multicolumn{3}{|c|}{ Infested water-controlled } & \multicolumn{3}{|c|}{ Uninfested water-controlled } & \multicolumn{3}{|c|}{ Infested water-stressed } & \multicolumn{3}{|c|}{ Uninfested water-stressed } \\
\hline & $0-24 h$ & $24-48 h$ & $48-72 h$ & $0-24 h$ & $24-48 \mathrm{~h}$ & $48-72 h$ & $0-24 h$ & $24-48 h$ & $48-72 h$ & $0-24 h$ & $24-48 h$ & $48-72 h$ \\
\hline \multicolumn{13}{|l|}{ Ketones } \\
\hline 6-Methyl hept-5-en-2-one & $1.15 \pm 0.13^{f}$ & $38.62 \pm 5.80^{a}$ & $3.04 \pm 0.73^{\mathrm{c}}$ & $0.56 \pm 0.12^{\mathrm{g}}$ & $5.80 \pm 0.87^{\text {cd }}$ & $7.77 \pm 1.69^{c}$ & $1.57 \pm 0.21^{\mathrm{F}}$ & $14.39 \pm 4.75^{b}$ & $14.50 \pm 2.35^{\mathrm{b}}$ & $5.04 \pm 0.41^{\text {cde }}$ & $4.64 \pm 0.50^{\text {ded }}$ & $3.85 \pm 0.84^{\text {sd }}$ \\
\hline Octan-2-one & $5.26 \pm 1.22^{\mathrm{b}}$ & $4.76 \pm 1.97^{\mathrm{k}}$ & $13.40 \pm 2.91^{\mathrm{a}}$ & nd & nd & nd & $2.45 \pm 0.88^{\mathrm{dd}}$ & $13.84 \pm 1.82^{n}$ & $1.85 \pm 0.88^{d}$ & nd & nd & nd \\
\hline
\end{tabular}




\section{Macrothink

\begin{tabular}{|c|c|c|c|c|c|c|c|c|c|c|c|c|}
\hline Total ketones & $6.41 \pm 1.10^{d}$ & $43.38 \pm 7.74^{\circ}$ & $16.44 \pm 3.59 \mathrm{c}$ & $0.56 \pm 0.12^{e}$ & $5.80 \pm 0.87^{d}$ & $7.77 \pm 1.6^{99^{d}}$ & $4.02 \pm 0.81^{d}$ & $28.23 \pm 4.68^{b}$ & $16.35 \pm 3.13^{c}$ & $5.04 \pm 0.41^{d}$ & $4.64 \pm 0.50^{\mathrm{d}}$ & $3.85 \pm 0.84^{d}$ \\
\hline \multicolumn{13}{|l|}{ Isothiocyanates (TTC) } \\
\hline 4-Methylpentyl ITC & trace & trace & $2.04 \pm 0.74^{b}$ & nd & nd & nd & trace & $2.11 \pm 0.23^{b}$ & $4.62 \pm 0.49^{\mathrm{a}}$ & nd & nd & nd \\
\hline \multicolumn{13}{|l|}{ Sulfide } \\
\hline Dimethyl disulfide & $0.62 \pm 0.25^{c}$ & $2.48 \pm 1.17^{\mathrm{b}}$ & $2.43 \pm 0.59^{b}$ & nd & nd & nd & trace & trace & $3.98 \pm 0.75^{a}$ & nd & nd & nd \\
\hline
\end{tabular}

VOC = volatile organic compound; nd $=$ not detected; trace $(<0.05 \%)$. For each individual VOC or each chemical family, mean values labeled with the same letter in the same row did not statistically differ ( $\mathrm{p}>0.05$, three-way ANOVA, post hoc Tukey's HSD test).

Table 1 (continued). Mean relative abundance $(\% \pm \mathrm{SD} ; \mathrm{n}=3)$ of VOCs emitted by water-controlled and water-stressed A. thaliana prior to infestation by $M$. persicae over three sampling periods (0-24 h, 24-48 h, and 48-72 h)

\begin{tabular}{|c|c|c|c|c|c|c|c|c|c|c|c|c|}
\hline \multirow{3}{*}{ Compound } & \multicolumn{12}{|c|}{ VOC proportion (\%) } \\
\hline & \multicolumn{3}{|c|}{ Infested water-controlled } & \multicolumn{3}{|c|}{ Uninfested water-controlled } & \multicolumn{3}{|c|}{ Infested water-stressed } & \multicolumn{3}{|c|}{ Uninfested water-stressed } \\
\hline & $0-24 h$ & $24-48 \mathrm{~h}$ & $48-72 h$ & $0-24 \mathrm{~h}$ & $24-48 \mathrm{~h}$ & $48-72 h$ & $0-24 \mathrm{~h}$ & $24-48 \mathrm{~h}$ & $48-72 h$ & $0-24 h$ & $24-48 \mathrm{~h}$ & $48-72 h$ \\
\hline \multicolumn{13}{|l|}{ Terpenes } \\
\hline Limonene & $5.55 \pm 1.34^{-\mathrm{d}}$ & $8.50 \pm 0.73^{\mathrm{c}}$ & $5.14 \pm 1.08^{d \mathrm{~d}}$ & $0.76 \pm 0.06^{6}$ & $1.20 \pm 0.52^{\mathrm{e}}$ & $5.78 \pm 0.74^{d d}$ & $32.67 \pm 4.83^{x}$ & $25.54 \pm 3.57^{\mathrm{th}}$ & $45.50 \pm 5.96^{a}$ & $1.45 \pm 0.29^{\circ}$ & $17.27 \pm 5.32^{b}$ & $4.01 \pm 0.54^{4}$ \\
\hline Menthol & $12.07 \pm 1.54^{\text {sad }}$ & $6.38 \pm 1.02^{\mathrm{d}}$ & $9.60 \pm 0.70^{\mathrm{d}}$ & $40.08 \pm 6.87^{n}$ & $12.66 \pm 2.32^{\mathrm{kdd}}$ & $9.21 \pm 1.57^{\mathrm{d}}$ & $19.93 \pm 3.05^{b}$ & $10.18 \pm 0.66^{6 d}$ & $7.47 \pm 0.82^{\mathrm{d}}$ & $43.19 \pm 3.28^{\mathrm{n}}$ & $17.53 \pm 1.24^{4 x}$ & $18.50 \pm 2.73^{b}$ \\
\hline$(E, E)-\alpha$-Farnesene & $9.44 \pm 0.68 \mathrm{c}$ & $14.26 \pm 3.33^{\text {ab }}$ & $17.50 \pm 1.01^{a}$ & nd & nd & nd & $13.35 \pm 2.52^{\text {ab }}$ & $12.31 \pm 1.68^{\mathrm{kx}}$ & $0.74 \pm 0.19^{d}$ & nd & nd & nd \\
\hline Total terpenes & $27.06 \pm 3.23^{1 / 8}$ & $29.15 \pm 4.84^{\text {fin }}$ & $32.23 \pm 0.53^{x^{\sqrt{18}}}$ & $40.84 \pm 6.83^{\text {cde }}$ & $13.86 \pm 2.84^{b}$ & $14.98 \pm 2.07^{\mathrm{h}}$ & $65.95 \pm 3.91^{\mathrm{A}}$ & $48.03 \pm 2.39^{\text {be }}$ & $53.71 \pm 5.28^{\mathrm{b}}$ & $44.64 \pm 3.53^{\text {bed }}$ & $34.80 \pm 5.62^{\text {def }}$ & $22.51 \pm 2.37^{\text {th }}$ \\
\hline
\end{tabular}

VOC $=$ volatile organic compound; nd $=$ not detected; trace $(<0.05 \%)$. For each individual VOC or each chemical family, mean values labeled with the same letter in the same row did not statistically differ ( $\mathrm{p}>0.05$, three-way ANOVA, post hoc Tukey's HSD test). 


\section{Discussion}

The present results demonstrate that aphid-infested water-stressed Arabidopsis exhibit significant changes in their VOC emission profile (Figures. 1, 2 and Table 1). The results were carried out by comparing the volatile profiles of water-treated plants uninfested and infested by aphids over the three time periods. Moreover, blank analyses were also conducted. Similar observations have been reported by Copolovici et al. (2014) in studies of well-watered versus drought-stressed Alnus glutinosa leaves infested by the green alder sawfly, Monsoma pulveratum.

The production of GS-derived volatiles by A. thaliana has been shown to be induced by aphid infestations (Mewis et al., 2005; Van Poecke, 2007; Ma and Ma, 2012; Truong et al., 2014). Similarly, in the present study, GS hydrolysis products, such as 4-methylpentyl ITC and DMDS, were detected in the VOC emission profiles of both water-controlled and water-stressed Arabidopsis infested by $M$. persicae. In particular, the proportion of 4-methylpentyl ITC was the highest for the infested water-stressed plants over the last two sampling periods (Table 1). It is hypothesized that ITCs (e.g., methylthio-, methylsulfinyland methylsulfonyl-ITC) are generated by myrosinase-mediated degradation of GS molecules, which occurs when an aphid stylet is inserted into the phloem, hence favoring enzyme-substrate contact (Kim and Jander, 2007; Van Poecke, 2007; Louis and Shah, 2013). Additionally, del Carmen Martínez-Ballesta et al. (2013) reviewed that water stress lead to an increased GS accumulation in Brassica species. It is demonstrated that the alteration in GS content in broccoli (Brassica oleracea var. italica) in response to M. persicae infestation depended on plant water availability (Khan et al., 2011). In the interaction of Arabidopsis and combined water and insect stress, Mewis et al. (2012) reported that the production of aliphatic GS from water-stressed Arabidopsis infested with $M$. persicae is associated with down-regulation of the biosynthetic genes, MAM1, CYP79F1, CYP83A1, and UGT74C1. Tariq et al. (2013) found that GS concentrations (aliphatic and indole) greatly increased in Brussels sprout plants (Brassica oleracea L. var. gemmifera cv. Oliver) exposed to combined drought stress and root herbivory (Delia radicum L.). Based on these evidences, the interaction between water stress and aphid feeding can lead to altered 4-methylpentyl ITC production in this study.

Published studies found that in Brassica species, the enzymatic thiol methyltransferase (TMT) have a strong influence on the hydrolysis of GS products to volatile sulfides (e.g., DMDS and dimethyl trisulfide (DMTS)) (Attieh et al., 2002; van Dam et al., 2012). It is reported that the artificial and natural damage to B. napus (L.) and B. juncea (L.) roots led to highest TMT activities in their leaves (van Dam et al., 2012). Existing data indicate that the physical conditions and herbivorous insects are extremely potent in the release of sulfur volatiles (Dugravot et al., 2005; Rouseff et al., 2008). In M. persicae-A. thaliana interaction, Kempema et al. (2007) demonstrated that aphid feeding caused up-regulation of two sulfurtransferase-like protein genes (Atg26280 and At1g29170) and greatly increased repression of 13 GS genes. In general, based on the existing literatures, the Arabidopsis sulfide production due to aphid-water stress interaction is still unclear. 
In the present study, emission of terpenes (e.g., limonene and menthol) from water-stressed Arabidopsis increased compared with water-controlled Arabidopsis (Figure 2F and Table 1). This observation is consistent with the results of Gouinguené and Turlings (2002), Ormeno et al. (2007), and Wenda-Piesik (2011), where the emission of induced VOCs (e.g., monoterpene and sesquiterpene) were found to be higher for plants exposed to dry soil or drought stress conditions. Correspondingly, it has been suggested that the release of terpenes by plants is dependent on leaf vapor pressure (Holopainen and Gershenzon, 2010; Loreto and Schnitzler, 2010). In corn (Zea mays L.) plants infested by the Spodoptera littoralis caterpillar, Gouinguené and Turlings (2002) detected higher emissions of $(E, E)$ - $\alpha$-farnesene and (3E)-4,8-dimethyl-1,3,7-nonatriene (DMNT) when the corn were cultivated on dry soils. Similarly, in the present study, the combination of $M$. persicae feeding and conditions of water-stress led to an increase in the proportion of terpenes emitted by Arabidopsis compared to the Arabidopsis that were only subjected to a single stress (Figure 2F and Table 1). It has been hypothesized that insect-infested plants may invest more resources in the biosynthetic production of induced defense compounds under water stress conditions (Gouinguené and Turlings, 2002). Wenda-Piesik (2011) also observed an increase in the amount of terpenes emitted by insect (Fusarium spp.)-infested winter wheat plants under water stress conditions.

Similar to the terpene results, a higher proportion of aldehyde and ketone emissions were detected for the infested water-stressed plants compared with the uninfested plants over the three assayed sampling periods (Figure 2, B \& C). In contrast, a higher proportion of alcohols were emitted by the water-stressed plants that were not subjected to aphid feeding (Figure 2A). Existing data indicate that the emissions of aldehydes, ketones, and alcohols are related to stomatal behavior under water stresses or infestations by aphids (Chen et al., 2003; Filella et al., 2009; Loreto and Schnitzler, 2010; Giorgi et al., 2012). For example, Giorgi et al. (2012) found an increase in ketone emission in M. persicae-infested Achillea collina compared with uninfested plants. However, the physiological state and corresponding mechanistic details that lead to the release of VOCs remain unclear (Holopainen and Gershenzon, 2010; Loreto and Schnitzler, 2010).

In conclusion, the present results demonstrate that water-controlled and water-stressed $A$. thaliana exhibit significant changes in their emission of VOCs (Figures 1, 2 and Table 1). Furthermore, when $M$. persicae feeding was an added stress for these two sets of water conditions, the emission of specific plant VOCs was induced. Thus, the present findings ascertain that abiotic stress factors may greatly interact to biotic stresses, and the impact of such combinations can modify VOC emission profiles for plants.

\section{Acknowledgement}

Dieu-Hien Truong is recipient of a PhD scholarship from Ministry of Education and Training Vietnam. We thank to Dr. François Verheggen (Laboratory of Functional \& Evolutionary Entomology, Gembloux Agro-Bio Tech, University of Liège) for his helpful collaboration.

\section{References}

Attieh, J., Djiana, R., Koonjul, P., Etienne C., Sparace S. A., \& Saini H. S. (2002). Cloning 
and functional expression of two plant thiol methyltransferases: A new class of enzymes involved in the biosynthesis of sulfur volatiles. Plant Mol Biol, 50(3), 511-521.

Chen, F., Tholl, D., D'Auria, J. C., Farooq, A., Pichersky, E., \& Gershenzon, J. (2003). Biosynthesis and emission of terpenoid volatiles from Arabidopsis flowers. Plant Cell, 15(2), 481-494.

Copolovici, L., Kannaste, A., Pazouki, L., \& Niinemets, U. (2012). Emissions of green leaf volatiles and terpenoids from Solanum lycopersicum are quantitatively related to the severity of cold and heat shock treatments. J Plant Physiol, 169(7), 664-672.

Copolovici, L., Kännaste, A., Remmel, T., \& Niinemets, T. (2014). Volatile organic compound emissions from Alnus glutinosa under interacting drought and herbivory stresses. Environmental and Experimental Botany, 100, 55-63.

De Vos, M., \& Jander G. (2010). Volatile communication in plant-aphid interactions. Curr Opin Plant Biol, 13(4), 366-371.

De Vos, M., \& Jander, G. (2009). Myzus persicae (green peach aphid) salivary components induce defence responses in Arabidopsis thaliana. Plant Cell Environ, 32(11), 1548-1560.

del Carmen Martínez-Ballesta M., Moreno, D. A., \& Carvajal, M. (2013). The Physiological Importance of Glucosinolates on Plant Response to Abiotic Stress in Brassica. International Journal of $\quad$ Molecular $\quad$ Sciences, 14607-11625. http://dx.doi.org/10.3390/ijms140611607

Diallo, D., \& Mariko, A. (2013). Field capacity (FC) and permanent wilty point (PWP) of clay soils developed on Quaternary alluvium in Niger River loop (Mali). International Journal of Engineering Research and Applications 3(1), 1085-1089.

Dicke, M., van Loon, J. J., \& Soler, R. (2009). Chemical complexity of volatiles from plants induced by multiple attack. Nat Chem Biol, 5(5), 317-324.

Dugravot, S., Mondy, N., Mandon, N., \& Thibout, E. (2005). Increased sulfur precursors and volatiles production by the leek Allium porrum in response to specialist insect attack. $J$ Chem Ecol, 31(6), 1299-1314.

Ebel, R. C., Mattheis, J. P., \& Buchanan, D. A. (1995). Drought stress of apple trees alters leaf emissions of volatile compounds. Physiologia Plantarum, 93(4), 709-712. http://dx.doi.org/10.1111/j.1399-3054.1995.tb05120.x

Filella I., Peñuelas, J., \& Seco, R. (2009). Short-chained oxygenated VOC emissions in Pinus halepensis in response to changes in water availability.

Giorgi, A., Panseri, S., Masachchige, C., Nanayakkara, N., \& Chiesa, L. (2012). HS-SPME-GC/MS analysis of the volatile compounds of Achillea collina: Evaluation of the emissions fingerprint induced by Myzus persicae infestation. Journal of Plant Biology, 55(3), 251-260. http://dx.doi.org/10.1007/s12374-011-0356-0

Gouinguené, S. P., \& Turlings, T. C. J. (2002). The effects of abiotic factors on induced volatile emissions in corn plants. Plant Physiology, 129(3), 1296-1307.

Hatano, E., Kunert, G., Michaud, J. P., \& Weisser, W. W. (2008). Chemical cues mediating aphid location by natural enemies. European Journal of Entomology, 105(5), 797-806.

Holopainen, J. K., \& Gershenzon, J. (2010). Multiple stress factors and the emission of plant 
VOCs. Trends in Plant Science, 15(3), 176-184.

Jones, H. G. (1998). Stomatal control of photosynthesis and transpiration. Journal of Experimental Botany, 49(Special 387-398. http://dx.doi.org/10.1093/jxb/49.Special_Issue.387

Kempema, L. A., Cui, X., Holzer, F. M., \& Walling, L. L. (2007). Arabidopsis transcriptome changes in response to phloem-feeding silverleaf whitefly nymphs. Similarities and distinctions in responses to aphids. Plant Physiol, 143(2), 849-865.

Khan, M. A. M., Ulrichs, C., \& Mewis, I. (2011). Water stress alters aphid-induced glucosinolate response in Brassica oleracea var. italica differently. Chemoecology, 21(4), 235-242. http://dx.doi.org/10.1007/s00049-011-0084-4

Kim, J. H., \& Jander, G. (2007). Myzus persicae (green peach aphid) feeding on Arabidopsis induces the formation of a deterrent indole glucosinolate. Plant J, 49(6), 1008-1019.

Kos, M., Houshyani, B., Achhami, B. B., Wietsma, R., Gols, R., Weldegergis, B. T., Kabouw, P., Bouwmeester, H. J., Vet, L. E., Dicke, M., \& van Loon, J. J. (2012). Herbivore-mediated effects of glucosinolates on different natural enemies of a specialist aphid. J Chem Ecol, $38(1), 100-115$.

Llusia, J., \& Penuelas, J. (1998). Changes in terpene content and emission in potted Mediterranean woody plants under severe drought. Can. J. Bot., 76, 1366-1373.

Loreto, F., \& Schnitzler, J. P. (2010). Abiotic stresses and induced BVOCs. Trends in Plant Science, 15(3), 154-166.

Louis, J., \& Shah, J. (2013). Arabidopsis thaliana-Myzus persicae interaction: shaping the understanding of plant defense against phloem-feeding aphids. Front Plant Sci, 4(213).

Louis, J., Singh, V., \& Shah, J. (2012). Arabidopsis thaliana-Aphid interaction. Arabidopsis Book 10(10), e0159. http://dx.doi.org/10.1199/tab.0159

Ma, G., \& Ma, C. S. (2012). Effect of acclimation on heat-escape temperatures of two aphid species: Implications for estimating behavioral response of insects to climate warming. $J$ Insect Physiol, 58(3), 303-309.

Mewis, I., Appel, H. M., Hom, A., Raina, R., \& Schultz, J. C. (2005). Major signaling pathways modulate Arabidopsis glucosinolate accumulation and response to both phloem-feeding and chewing insects. Plant Physiol, 138(2), 1149-1162.

Mewis, I., Khan, M. A. M., Glawischnig, E., Schreiner, M., \& Ulrichs, C. (2012). Water stress and aphid feeding differentially influence metabolite composition in Arabidopsis thaliana (L. ). PLoS ONE, 7(11), e48661.

Niinemets, Ü., Kännaste, A., \& Copolovici, L. (2013). Quantitative patterns between plant volatile emissions induced by biotic stresses and the degree of damage. Frontiers in Plant Science, 4. http://dx.doi.org/10.3389/fpls.2013.00262

Niinemets, Ü., Loreto, F., \& Reichstein, M. (2004). Physiological and physicochemical controls on foliar volatile organic compound emissions. Trends Plant Sci, 9(4), 180-186.

Ormeno, E., Mevy, J. P., Vila, B., Bousquet-Melou, A., Greff, S., Bonin, G., \& Fernandez, C. (2007). Water deficit stress induces different monoterpene and sesquiterpene emission changes in Mediterranean species. Relationship between terpene emissions and plant water 
potential. Chemosphere, 67(2), 276-284.

Peñuelas, J., \& Llusià, J. (1997). Effects of carbon dioxide, water supply, and seasonality on terpene content and emission by Rosmarinus officinalis. Journal of Chemical Ecology, 23(4), 979-993. http://dx.doi.org/10.1023/B:JOEC.0000006383.29650.d7

Rouseff, R. L., Onagbola, E. O., Smoot, J. M., \& Stelinski, L. L. (2008). Sulfur volatiles in guava (Psidium guajava L. ) leaves: possible defense mechanism. J Agric Food Chem, 56(19), 8905-8910.

Sales, R. M. P., Fries, D. D., Bonomo, P., Pires, A. J. V., Campos, C. N., Brito, P. H. R., Pereira, I. S., \& Santos, J. d. S. (2013). Effect of water stress on the growth of Arachis pintoi plants under different nitrogen levels. Revista Brasileira de Zootecnia, 42, 149-154.

Staudt, M., Rambal, S., Joffre, R., \& Kesselmeier, J. (2002). Impact of drought on seasonal monoterpene emissions from Quercus ilex in southern France. Journal of Geophysical Research: Atmospheres, 107(D21), 4602. http://dx.doi.org/10.1029/2001jd002043

Suzuki, N., Rivero, R. M., Shulaev, V., Blumwald, E., \& Mittler, R. (2014). Abiotic and biotic stress combinations. New Phytol, 203(1), 32-43.

Tardieu, F., \& Simonneau, T. (1998). Variability among species of stomatal control under fluctuating soil water status and evaporative demand: modelling isohydric and anisohydric behaviours. J Exp Bot 49, 419-432.

Tariq, M., Rossiter, J. T., Wright, D. J., \& Staley, J. T. (2013). Drought alters interactions between root and foliar herbivores. Oecologia, 172(4), 1095-1104.

Tholl, D., Boland, W., Hansel, A., Loreto, F., Röse, U. S. R., \& Schnitzler, J. P. (2006). Practical approaches to plant volatile analysis. Plant Journal, 45(4), 540-560.

Truong, D. H., Delory, B. M., Vanderplanck, M., Brostaux, Y., Vandereycken, A., Heuskin, S., Delaplace, P., Francis, F., \& Lognay, G. (2014). Temperature regimes and aphid density interactions differentially influence VOC emissions in Arabidopsis. Arthropod-Plant Interactions, 8(4), 317-327. http://dx.doi.org/10.1007/s11829-014-9311-6

Vallad, G. E., \& Goodman, R. M. (2004). Systemic acquired resistance and induced systemic resistance in conventional agriculture. Crop Science, 44(6), 1920-1934.

Vallat, A., Gu, H., \& Dorn, S. (2005). How rainfall, relative humidity and temperature influence volatile emissions from apple trees in situ. Phytochemistry, 66(13), 1540-1550.

van Dam, N. M., Samudrala, D., Harren, F. J., \& Cristescu, S. M. (2012). Real-time analysis of sulfur-containing volatiles in Brassica plants infested with root-feeding Delia radicum larvae using proton-transfer reaction mass spectrometry. AoB Plants, 10, 20.

Van Poecke, R. M. P. (2007). Arabidopsis-insect interactions Somerville CR, Meyerowitz EM, eds. The Arabidopsis book (pp. 1-34). Rock-ville: MD: American Society of Plant Biologists.

Verdugo, J. A. (2012). Defensive response of commercial varieties of Prunus persica L. to the attack of Myzus persicae (Sulzer) aphid. Thèse de Doctoral, Université de LiègeGembloux Agro-Bio Tech (Belgique).

Vickers, C. E., Gershenzon, J., Lerdau, M. T., \& Loreto F. (2009). A unified mechanism of action for volatile isoprenoids in plant abiotic stress. Nat Chem Biol, 5(5), 283-291. 
Walling, L. L. (2000). The myriad plant responses to herbivores. J Plant Growth Regul, 19(2), 195-216.

Wenda, P. A. (2011). Volatile organic compound emissions by winter wheat plants (Triticum aestivum L. ) under Fusarium spp. infestation and various abiotic conditions. Pol. J. Environ. Stud., 20(5), 1335-1342.

\section{Copyright Disclaimer}

Copyright for this article is retained by the author(s), with first publication rights granted to the journal.

This is an open-access article distributed under the terms and conditions of the Creative Commons Attribution license (http://creativecommons.org/licenses/by/3.0/). 